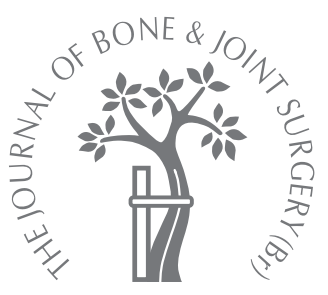

H. C. Lim,

J. H. Bae,

C. R. Hur,

J. K. Oh,

S. H. Han

From Korea

University College of

Medicine, Guro

Hospital, Seoul,

Korea
H. C. Lim, MD, PhD, Professor

J. H. Bae, MD, Clinical

Associate Professor

ㄷ. C. R. Hur, MD, PhD, Professor

J. K. Oh, MD, PhD, Professor

I. H. Han, MD, Clinical

Associate Professor

Department of Orthopaedic

Surgery

Korea University College of

Medicine, Guro Hospital, 80

Guro-dong, Guro-gu, Seoul

152-703, Korea.

Correspondence should be sent

to $\mathrm{Dr}$ J. H. Bae; e-mail:

osman@korea.ac.kr

(C)2009 British Editorial Society

of Bone and Joint Surgery

doi:10.1302/0301-620X.91B2.

$21043 \$ 2.00$

$J$ Bone Joint Surg $[\mathrm{Br}]$ 2009;91-B:180-4.

Received 17 March 2008;

Accepted after revision 16

September 2008

\title{
Arthrodesis of the knee using cannulated
}

\section{screws}

We retrospectively evaluated eight patients who underwent arthrodesis of the knee using cannulated screws. There were six women and two men, with a mean age of 53 years. The indications for arthrodesis were failed total knee arthroplasty, septic arthritis, tuberculosis, and recurrent persistent infection. Solid union was achieved in all patients at a mean of 6.1 months. One patient required autogenous bone graft for delayed union. One suffered skin necrosis which was treated with skin grafting. The mean limb-length discrepancy was $3.1 \mathrm{~cm}$. On a visual analogue scale, the mean pain score improved from 7.9 to 3.3 . According to the Knee Injury and Osteoarthritis Outcome score quality of life items, the mean score improved from $\mathbf{3 8 . 3}$ pre-operatively to $\mathbf{7 6 . 6}$ at follow-up. Cannulated screws provide a high rate of union in arthrodesis of the knee with minimal complications, patient convenience, and a simple surgical technique.

Arthrodesis may be used to obtain a stable, painless knee in a patient with a failed arthroplasty, septic arthritis, peri-articular tumour, or recurrent infection. Successful fusion may be obtained in $80 \%$ to $98 \%$ of patients. ${ }^{1-6}$ Various techniques have been described. External fixation may use uniplanar, ${ }^{7}$ modified biplanar frames with transfixation pins and half pins, ${ }^{8,9}$ or circular frames. ${ }^{10-12}$ Methods of internal fixation include an anterior plate, ${ }^{13}$ double plating, ${ }^{14}$ an antegrade locking nail, ${ }^{15-17}$ combined intramedullary nailing and plate fixation, ${ }^{18}$ and modular intramedullary nails. ${ }^{19} \mathrm{No}$ single technique has proved to be superior in all situations.

The purpose of this study was to evaluate the outcome after arthrodesis of the knee using cannulated screws.

\section{Patients and Methods}

Eight patients who underwent arthrodesis of the knee using cannulated screws (Synthes, Paoli, Pennsylvania) between 1998 and 2005 were evaluated retrospectively (Table I). There were six women and two men, with a mean age of 58.3 years (36 to 76 ). The indications for arthrodesis were failed total knee replacement (TKR) in two, soft tissue and bone loss in one, tuberculosis in three, and recurrent infection in two.

In the six patients with infection arthrodesis was not undertaken until it had been eradicated. On the basis of culture and sensitivity testing, appropriate intravenous antibiotics were administered for four to six weeks, or anti-tuberculous medication for 9 to 12 months or until the serum levels of inflammatory markers had become normal.

The loss of bone at operation was classified as mild, moderate or severe. ${ }^{6,20}$ It was considered to be mild if full bony contact was possible, moderate if there was incomplete bony contact and severe if there was minimal bony contact. Bone loss was mild in two patients, moderate in three and severe in three.

Pain was assessed using a visual analogue scale from zero to 10 , with 10 being the most painful. The Short Form-36 Health Survey (SF36) was used as a measure of general health status, and each of the eight subscales had a score of zero to 100 , with 100 being the best score. ${ }^{21}$ Quality of life was assessed using four questions $^{20}$ from the Knee Injury and Osteoarthritis Outcome Score (KOOS) questionnaire, which has been validated for the evaluation of patients undergoing knee injury, with 100 being the best outcome. ${ }^{22}$

Serial radiographs were used to determine the time of fusion. Clinical and radiographic union were defined as the ability to walk without pain, no tenderness at the site of the arthrodesis and the appearance of trabecular bone bridging at the site of arthrodesis on both anteroposterior and lateral radiographs. The alignment of the limb and leg-length discrepancy were measured on full-length radiographs taken after union had been achieved. 
Table I. Details of the patients who underwent arthrodesis of the knee

\begin{tabular}{|c|c|c|c|c|c|c|c|c|}
\hline Number & $\begin{array}{l}\text { Age } \\
\text { r (yrs) }\end{array}$ & Gender & Co-morbidities* & Previous surgery & Indication & $\begin{array}{l}\text { Type of } \\
\text { bone loss }\end{array}$ & $\begin{array}{l}\text { Time to fusion } \\
\text { (mths) }\end{array}$ & Complication \\
\hline 1 & 50 & $\mathrm{~F}$ & RA & Arthroscopic debridement and irrigation & Recurrent infection & Mild & 5 & None \\
\hline 2 & 54 & $\mathrm{~F}$ & None & Open debridement and irrigation & Septic arthritis sequelae & Moderate & 6 & Skin necrosis \\
\hline \multirow[t]{2}{*}{3} & 36 & $\mathrm{~F}$ & None & Implant removal and open debridement & Infected TKR & & & \\
\hline & & & & & Tuberculosis & Severe & 8 & $\begin{array}{l}\text { Delayed } \\
\text { union }\end{array}$ \\
\hline 4 & 76 & $\mathrm{~F}$ & $\mathrm{DM}+$ & Open debridement and irrigation & Recurrent infection & Mild & 4 & None \\
\hline 5 & 64 & $\mathrm{M}$ & Obesity & TKR & Failed TKR (Charcot joint) & Severe & 5 & None \\
\hline 6 & 68 & $\mathrm{~F}$ & None & $\begin{array}{l}\text { Open debridement and insertion of a } \\
\text { cement spacer }\end{array}$ & Tuberculosis & Moderate & 4 & None \\
\hline 7 & 55 & $\mathrm{M}$ & None & Open debridement & Tuberculosis & Moderate & 5 & None \\
\hline 8 & 63 & $\mathrm{~F}$ & $\begin{array}{l}\text { Chronic renal } \\
\text { failure }\end{array}$ & Implant removal and cement insertion & Infected TKR (MRSA§) & Severe & 6 & None \\
\hline
\end{tabular}

*RA, rheumatoid arthritis

† DM, diabetes mellitus

\# TKR, total knee replacement

$\S$ MRSA, Methicillin-resistant Staphylococcus aureus

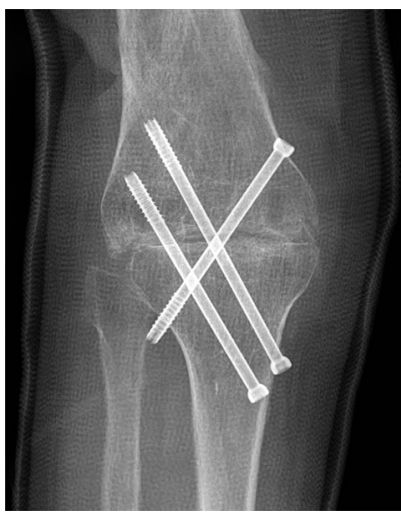

Fig. 1a

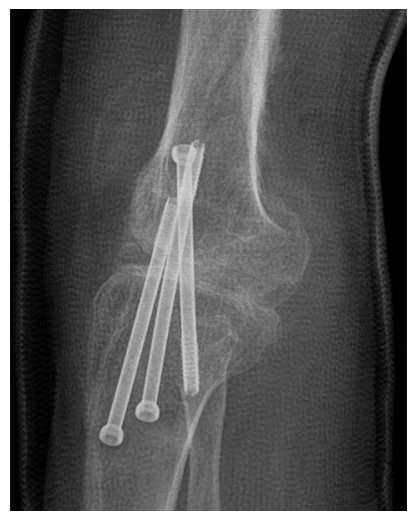

Fig. 1b

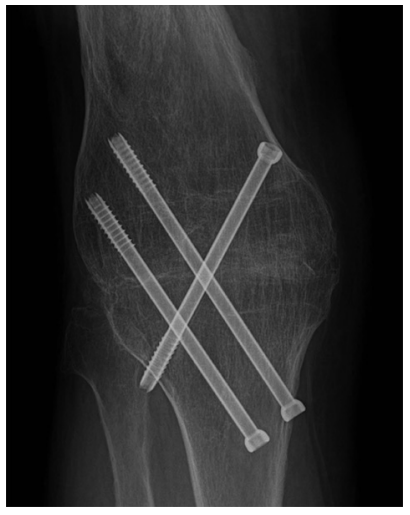

Fig. 1c

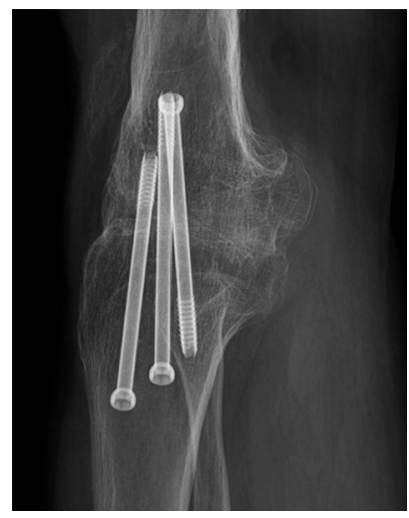

Fig. 1d

A 54-year-old woman with previous septic arthritis. Early post-operative radiographs showing a) and b) maximum bony contact and crossed cannulated screws and post-operative radiograph showing c) and d) showing a solid fusion three years later.

Surgical technique. The patient is supine and the leg draped from the buttock to the toes. Either a midline incision is used, or previous incisions as dictated by the condition of the skin. Skin flaps should not be undermined more than necessary, and should be handled with care to minimise damage to the cutaneous circulation. The patella is excised to relieve tension on the incision and to add to the site of the arthrodesis later. The menisci, cruciate ligaments and any debris are excised. Samples of fibrous tissue and bone are taken for microbiological studies. If present, the prosthetic components and all cement are removed with wide debridement and lavage. The bone ends are prepared with removal of all articular cartilage and the preparation of appropriate surfaces for apposition. In order to maintain limb length, minimal bone resection is performed when arthrodesis is undertaken after TKR. Autogenous iliac bone graft is used if there is marked loss of bone. Excised patella or autogenous iliac bone graft is used if there is moderate or severe bone loss. The femur and tibia are placed in $5^{\circ}$ to $7^{\circ}$ valgus and $0^{\circ}$ to $5^{\circ}$ flexion, and are fixed with two or three crossed cannulated screws (Figs 1 and 2). Two parallel screws are inserted to obtain compression, and a further screw is added to obtain resistance to shear stress.

A cylinder cast is retained for six to eight weeks with partial weight-bearing as tolerated. Full weight-bearing is allowed when there is radiological evidence of union.

\section{Results}

Primary union was achieved in seven patients $(87.5 \%)$. At a mean follow-up of 5.8 years (2.3 to 10$)$ all patients were able to walk without pain and none had evidence of instability or recurrent infection. The mean time to union was 6.1 months (4 to 8). Delayed union occurred in one patient (No 3, Table I) with severe bone loss, who 


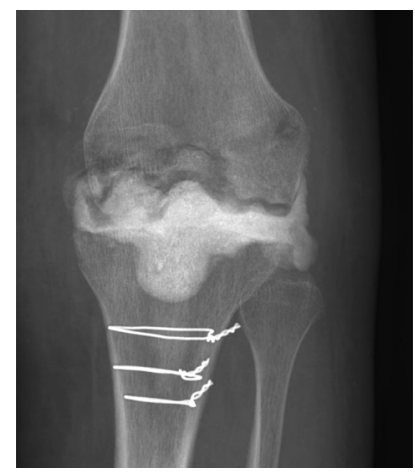

Fig. 2a

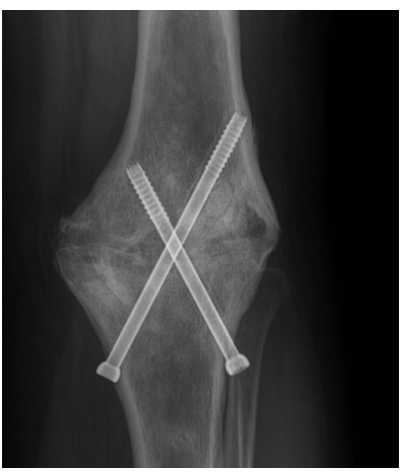

Fig. $2 b$

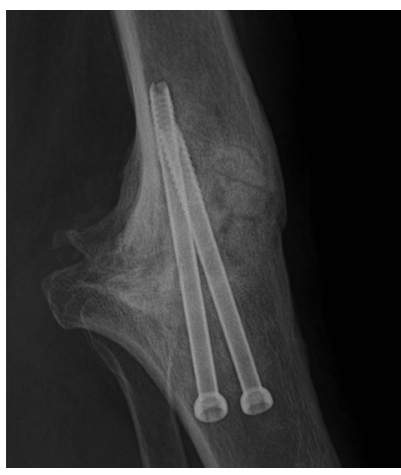

Fig. 2c

A 36-year-old woman with an infected total knee replacement. Radiographs showing (a) an antibiotic-loaded spacer inserted after removal of the components and b) and c) two years after arthrodesis showing sound fusion.

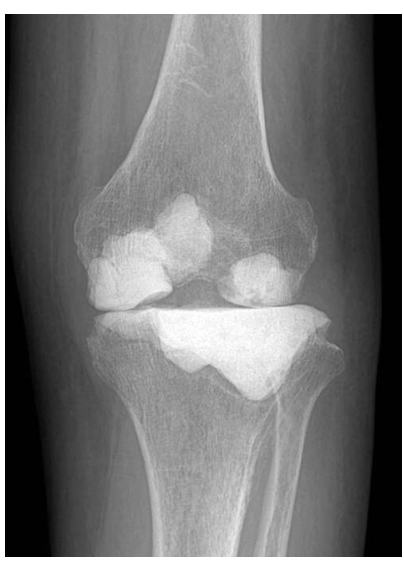

Fig. 3a

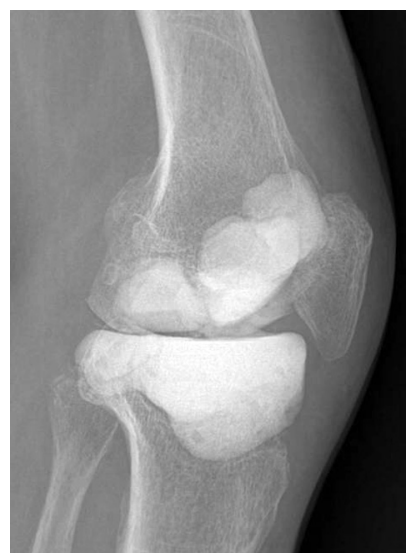

Fig. $3 b$

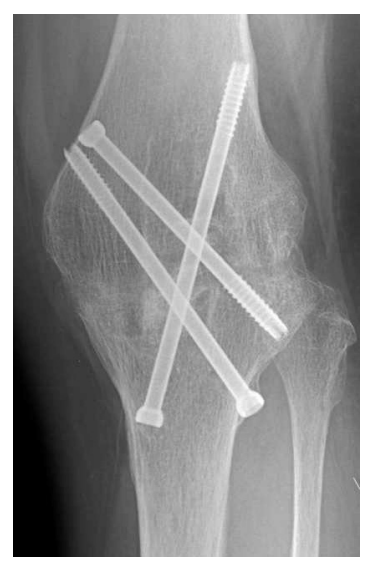

Fig. 3c

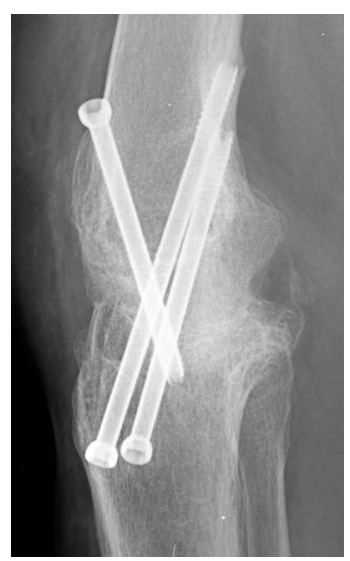

Fig. 3d

A 68-year-old woman with tuberculosis. Radiographs showing a) and b) moderate bone loss and an antibiotic-loaded cement spacer and c) and d) solid fusion two years after arthrodesis. Excised patella and autogenous iliac bone graft were used to manage the bone loss during operation.

Table II. General health status as measured with the Short-Form (SF)-36 at follow-up (data are given as the mean, with SD in parentheses)

\begin{tabular}{ll}
\hline & SF-36 score \\
\hline Physical functioning & $33.1(25.1)$ \\
Role physical & $30.9(28.9)$ \\
Bodily pain & $46.3(23.1)$ \\
General health & $47.2(26.2)$ \\
Vitality & $43.5(32.2)$ \\
Social functioning & $56.4(42.9)$ \\
Role emotional & $46.5(43.3)$ \\
Mental health & $58.3(17.7)$ \\
\hline
\end{tabular}

underwent a further bone grafting procedure six monthsafter the initial operation. Union was achieved two months later. One patient (No 2, Table I) had necrosis of the wound margins and required skin grafting. Two patients required autogenous iliac bone graft during arthodesis. Excised patella was used in patients with moderate or severe bone loss (Fig. 3).

The mean post-operative alignment was $4^{\circ}$ valgus $\left(0^{\circ}\right.$ to $\left.7^{\circ}\right)$ and the mean leg-length discrepancy was $3.1 \mathrm{~cm}(1.1$ to $6.5)$. Two patients had shortening of $>5.0 \mathrm{~cm}$. No patient had significant rotational deformity.

The mean Short-Form (SF-36) scores at follow-up are shown in Table II. The mean pain score improved from 7.9 ( 7 to 9 ) to 3.3 (2 to 4 ). The mean KOOS score improved from 38.3 (31.3 to 43.8 ) to 76.6 (62.5 to 87.5 )

\section{Discussion}

The techniques that are available to obtain arthrodesis of the knee may be categorised by the type of fixation used. ${ }^{7-19,23-25}$ We are not aware of descriptions of arthrodesis using fixation with cannulated screws. The rate of primary union in our patients was $87.5 \%$, with one patient requiring a secondary procedure. The mean time to union, 6.1 months, was similar to that in studies using other forms of fixation (Table III). 
Table III. Results of knee arthrodesis in the literature

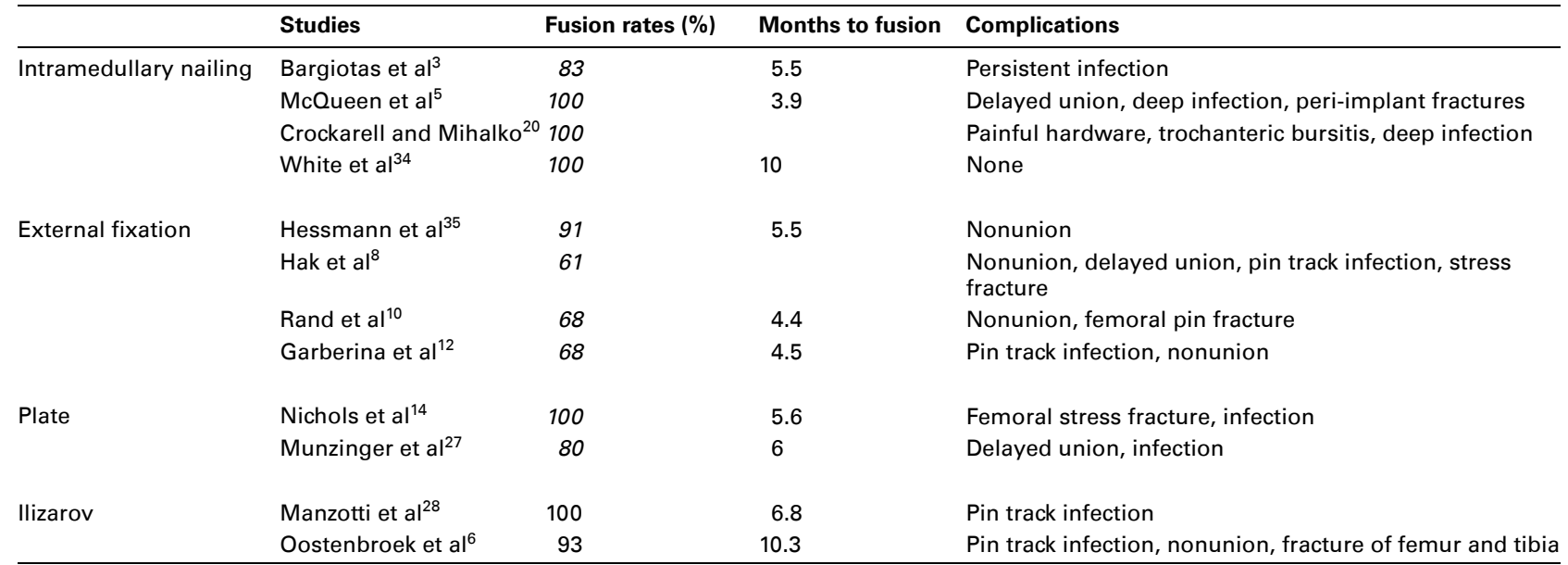

Each technique has advantages and disadvantages. Intramedullary nailing has a high rate of union and excellent stability, but has the risk of the intramedullary dissemination of any infection.3,5,26 Arthrodesis using an external fixator has been popular, but pin track infection and adjustments requiring hospital admission are common. ${ }^{12}$ Good rates of union have been achieved using compression plates, 14,27 but there are concerns about the risk of fracture at the bone-plate junction, and patients are often immobilised in an above-knee cast until fusion has occurred.14 Ilizarov techniques have been used more recently6,28 but require further operative procedures, and again have many complications such as pintrack infection, nonunion, fracture of the femur and tibia (Table III). Arthrodesis using cannulated screws is technically straightforward, convenient for patients, has a low rate of delayed union and of recurrence of infection, and compression can be obtained. The disadvantages of this technique are the need of immobilisation and delayed weight-bearing.

The causes of nonunion include poor bone stock, inadequate fixation, persistent infection, and lack of bony contact. ${ }^{23}$ Several authors have recommended iliac crest bone grafting when no signs of healing are present four months after the procedure. ${ }^{10,26,29,30}$ Arthrodesis using cannulated screws should be considered when there is minimal bone loss and broad cancellous surfaces with adequate cortical bone to allow good bony apposition and compression. Two patients with severe bone loss in our study achieved primary union without additional surgery.

The technique using cannulated screws is based on several studies of screw fixation for ankle arthrodesis. OgilvieHarris, Fitsialos and Hedman, ${ }^{31}$ in a biomechanical cadaver study, showed that three crossed screws generated significantly more compression and resistance to torque across the arthrodesis site than did two screws. They also found that better compression was obtained when the lateral screw was inserted first, and recommended placing one screw laterally, one medially and one anteriorly from the tibia to the talus. Mann et $\mathrm{al}^{32}$ also recommended two parallel cancellous screws, emphasising the excellent compression obtained by the parallel orientation of the screws. Friedmann, Glisson and Nunley, ${ }^{33}$ however, found that crossed screws were more rigid than parallel screws, especially in resisting the torsional stress. We recommend three crossed cannulated screws for arthrodesis of the knee. First, two parallel screws are inserted to obtain compression; a further crossed screw is then placed to obtain resistance to shear stress across the site of arthrodesis.

A limitation of our study is that the pre-operative SF-36 scores were not recorded.

We believe that arthrodesis of the knee using cannulated screws provides a high rate of union, minimal complications, patient convenience, and is a simple surgical technique. It may reduce the need for additional surgery or extensive post-operative rehabilitation. It is now our practice to use cannulated screws for arthrodesis of the knee, although alternative methods, such as intramedullary nailing, are considered when there is extensive bone loss and poor bone stock.

No benefits in any form have been received or will be received from a commercial party related directly or indirectly to the subject of this article.

\section{References}

1. Barton TM, White SP, Mintowt-Czyz W, Porteous AJ, Newman JH. A comparison of patient based outcome following knee arthrodesis for failed total knee arthroplasty and revision knee arthroplasty. Knee 2008;15:98-100.

2. Mabry TM, Jacofsky DJ, Haidukewych GJ, Hanssen AD. Comparison of intramedullary nailing and external fixation knee arthrodesis for the infected knee replacement. Clin Orthop 2007;464:11-15.

3. Bargiotas K, Wohlrab D, Sewecke JJ, et al. Arthrodesis of the knee with a long intramedullary nail following the failure of a total knee arthroplasty as the result of infection: surgical technique. J Bone Joint Surg [Am] 2007;89-A(Suppl 2):103-10.

4. Salem KH, Keppler P, Kinz L, Schmelz A. Hybrid external fixation for arthrodesis in knee sepsis. Clin Orthop 2006;451:113-20.

5. McQueen DA, Cooke FW, Hahn DL. Knee arthrodesis with the Wichita fusion nail: an outcome comparison. Clin Orthop 2006;446:132-9. 
6. Oostenbroek HJ, van Roermund PM. Arthrodesis of the knee after an infected arthroplasty using the llizarov method. J Bone Joint Surg [Br] 2001;83-B:50-4.

7. Cunningham JL, Richardson JB, Soriano RM, Kenwright J. A mechanical assessment of applied compression and healing in knee arthrodesis. Clin Orthop 1989;242:256-64.

8. Hak DJ, Lieberman JR, Finerman GA. Single plane and biplane external fixators for knee arthrodesis. Clin Orthop 1995;316:134-44.

9. Brooker AF Jr, Hansen NM Jr. The biplane frame: modified compression arthrodesis of the knee. Clin Orthop 1981;160:163-7.

10. Rand JA, Bryan RS, Chao EY. Failed total knee arthroplasty treated by arthrodesis of the knee using the Ace-Fischer apparatus. J Bone Joint Surg [Am]1987;69-A:39-45.

11. David R, Shtarker H, Horesh Z, Tsur A, Soudry M. Arthrodesis with the Ilizarov device after failed knee arthroplasty. Orthopedics 2001;24:33-6.

12. Garberina MJ, Fitch RD, Hoffmann ED, et al. Knee arthrodesis with circular external fixation. Clin Orthop 2001;382:168-78.

13. Pritchett JW, Mallin BA, Matthews AC. Knee arthrodesis with a tension-band plate. J Bone Joint Surg [Am] 1988;70-A:285-8.

14. Nichols SJ, Landon GC, Tullos HS. Arthrodesis with dual plates after failed total knee arthroplasty. J Bone Joint Surg [Am] 1991;73-A:1020-4.

15. Vlasak R, Gearen PE, Petty W. Knee arthrodesis in the treatment of failed total knee replacement. Clin Orthop 1995;321:138-44.

16. Enneking WF, Shirley PD. Resection-arthrodesis for malignant and potentially malignant lesions about the knee using an intramedullary rod and local bone grafts. $J$ Bone Joint Surg [Am] 1977;59-A:223-36.

17. Donley BG, Matthews LS, Kaufer H. Arthrodesis of the knee with an intramedullary nail. J Bone Joint Surg [Am] 1991;73-A:907-13.

18. StiehI JB, Hanel DP. Knee arthrodesis using combined intramedullary rod and plate fixation. Clin Orthop 1993;294:238-41.

19. Waldman BJ, Mont MA, Payman KR, et al. Infected total knee arthroplasty treated with arthrodesis using a modular nail. Clin Orthop 1999;367:230-7.

20. Klinger HM, Spahn G, Schultz W, Baums MH. Arthrodesis of the knee after failed infected total knee arthroplasty. Knee Surg Sports Traumatol Arthrosc 2006;14:447-53.
21. Bullinger M. German translation and psychometric testing of the SF-36 Health Survey: preliminary results from the I0OLA project. Soc Sci Med 1995;41:1359-66.

22. Rand JA. Alternatives to reimplantation for salvage of the total knee arthroplasty complicated by infection. J Bone Joint Surg [Am] 1993;75-A:282-9.

23. Arroyo JS, Garvin KL, Neff JR. Arthrodesis of the knee with a modular titanium intramedullary nail. J Bone Joint Surg [Am] 1997;79-A:26-35.

24. Fern ED, Stewart HD, Newton G. Curved Kuntscher nail arthrodesis after failure of knee replacement. J Bone Joint Surg [Br] 1989;71-B:588-90.

25. Ulstrup AK, Folkmar K, Broeng L. Knee arthrodesis with the Sheffield external ring fixator: fusion in 6 of 10 consecutive patients. Acta Orthop 2007;78:371-6.

26. Crockarell JR Jr, Mihalko MJ. Knee arthrodesis using an intramedullary nail. J Arthroplasty 2005;20:703-8.

27. Munzinger U, KnessI J, Gschwend N. Arthrodesis following knee arthroplasty. Orthopade 1987;16:301-9 (in German).

28. Manzotti A, Pullen C, Deromedis B, Catagni MA. Knee arthrodesis after infected total knee arthroplasty using the llizarov method. Clin Orthop 2001;389:143-9.

29. Behr JT, Chmell SJ, Schwartz CM. Knee arthrodesis for failed total knee arthroplasty. Arch Surg 1985;120:350-4.

30. Knutson K, Hovelius L, Lindstrand A, Lidgren L. Arthrodesis after failed knee arthroplasty: a nationwide multicenter investigation of 91 cases. Clin Orthop 1984;191:202-11.

31. Ogilvie-Harris DJ, Fitsialos D, Hedman TP. Arthrodesis of the ankle: a comparison of two versus three screw fixation in crossed configuration. Clin Orthop 1994;304:195-9.

32. Mann RA, Van Manen JW, Wapner K, Martin J. Ankle fusion. Clin Orthop 1991;268:49-55.

33. Friedman RL, Glisson RR, Nunley JA 2nd. A biomechanical comparative analysis of two techniques for tibiotalar arthrodesis. Foot Ankle Int 1994;15:301-5.

34. White SP, Porteous AJ, Newman JH, Mintowt-Czyz W, Barr V. Arthrodesis of the knee using a custom-made intramedullary coupled device. J Bone Joint Surg [Br] 2003;85-B:57-61.

35. Hessmann M, Gotzen L, Baumgaertel F. Knee arthrodesis with a unilateral external fixator. Acta Chir Belg 1996;96:123-7. 